Short communication

\title{
ANTIMICROBIAL RESISTANCE PATTERNS OF STAPHYLOCOCCUS AUREUS ISOLATED FROM BOVINE SUBCLINICAL MASTITIS IN ALBORZ PROVINCE, IRAN
}

\author{
H. POURTAGHI ${ }^{1}$, A. GHASEM AZIZI ${ }^{2} \&$ H. R. SODAGARI ${ }^{3}$ \\ ${ }^{1}$ Department of Microbiology, Karaj Branch, Islamic Azad University, Karaj, Iran; \\ ${ }^{2}$ Department of Biology, Borujerd Branch, Islamic Azad University, Borujerd, Iran; \\ ${ }^{3}$ Young Researchers and Elite Club, Karaj Branch, Islamic Azad University, Karaj, Iran
}

\section{Summary}

Pourtaghi, H., A. Ghasem Azizi \& H. R. Sodagari, 2016. Antimicrobial resistance patterns of Staphylococcus aureus isolated from bovine subclinical mastitis in Alborz province, Iran. Bulg. J. Vet. Med., 19, No 2, 169-174.

\begin{abstract}
The aim of this study was to determine antimicrobial resistance patterns of Staphylococcus aureus isolated from bovine subclinical mastitis. California Mastitis Test was used for 2,160 quarters of 540 dairy cattle in 8 commercial dairy farms of Alborz province, Iran. Antimicrobial susceptibility test was performed by the disk diffusion method on Mueller Hinton agar. The results indicated that Staphylococcus genus was isolated from 84 out of 420 milk samples collected from suspected quarters. Out of 84 positive samples, $50(59.5 \%)$ of them were reported as coagulase-positive $S$. aureus; 45 strains were further identified as Staphylococcus aureus by PCR amplification of the specific $23 \mathrm{~S}$ rDNA gene. All $S$. aureus isolates showed resistance against penicillin and ceftiofur but no resistance to gentamicin, enrofloxacin and lincomycin. In addition, $38(84.4 \%)$ of $S$. aureus isolates were resistant to at least 3 antimicrobial agents. According to the results ceftiofur, penicillin, ampicillin was the predominant pattern $(22.2 \%)$ among seven different antimicrobial resistance patterns. Therefore, carrying out antimicrobial susceptibility tests before drug prescription seems necessary.
\end{abstract}

Key words: bovine, resistance pattern, Staphylococcus aureus, subclinical mastitis

Inflammation of the mammary gland (mastitis) is identified by an increase in the number of somatic cells in the milk as well as pathological changes in the mammary tissue (Sharma, 2007). Mastitis in both clinical and subclinical forms is one of the most significant causes of economic losses to the dairy industry in Iran and other countries around the world (Seleim et al., 2002; Donovan et al., 2005; Huijps et al., 2008; Sahebekhtiari et al., 2011; Hosseinzadeh \& Dastmalchi Saei, 2014) due to reduced production and quality of milk and also high costs of treatment. The subclinical form of this disease is more important economically due to its higher prevalence (Rahim et al., 2010; Balqees, 2012). The milk of dairy animals with 
subclinical mastitis due to invisible changes can enter the bulk tank (Leitner et al., 2008) and may represent potential health hazard to milk and dairy products consumers (Jorgensen et al., 2005).

Among the wide spectrum of bacterial mastitis pathogens, Staphylococcus aure$u s$ is recognised as the most frequent isolate from clinical and subclinical bovine mastitis (Taponen et al., 2006). The high prevalence of this pathogen in milk has been attributed to poor hygiene practices (Ateba et al., 2010). The rapid detection of this pathogen in mastitis is significant to achieve treatment of the disease. Therefore, bacterial identification and susceptibility tests play important roles for selecting the appropriate antimicrobial agent when treating mastitis (Gentilini et al., 2000). Antibiotic resistance of $S$. aureus has been attributed to extensive utilisation of antibacterial agents in bovine mastitis which has been reported by several researchers (De Oliveira et al., 2000; Pitkala et al., 2004). This antimicrobial resistance may be due to the occurrence and transmission of antimicrobial-resistant strains of $S$. aureus or their genes (Lowy, 2003) which can be the major reason of low treatment rate of mastitis (Barkema et al., 2006; Gao et al., 2012). Therefore, the aim of the study was to determine the antimicrobial resistance of $S$. aureus isolates from subclinical bovine mastitis in Iran.

California Mastitis Test (CMT) was used for 2,160 quarters of 540 dairy cattle in 8 commercial farms of Alborz province, Iran. After cleaning the teats and dipping them in a disinfectant and also shedding the initial milking, sampling was done from 420 quarters with positive CMT test. Thirthy $\mathrm{mL}$ for each sample were collected into sterile tubes and immediately transported to laboratory under temperature-controlled conditions.
Somatic cell count (SCC) of collected milk samples was estimated in the laboratory. Bacterial culturing of milk samples which had SCC greater than 200,000 $\mathrm{cfu} / \mathrm{mL}$ were done. For bacteria identification, a loopful of each collected milk sample was streaked on blood agar, Mac Conkey agar and Baird Parker agar. After growth, staphylococci were identified on the basis of colony characteristics, Gram staining, pigment production, haemolysis and the following biochemical reactions: catalase activity and oxidase test. Tube coagulase test was done to detect the type of Staphylococcus, also PCR on 23S rDNA gene was used with a few modification. (Straub et al., 1999). Briefly, DNA extraction was performed using a boiling method as a DNA template. Three overnight cultures in $2 \mathrm{~mL}$ nutrient broth were centrifuged for $5 \mathrm{~min}$ at $5,000 \mathrm{rpm}$. The bacterial pellet was re-suspended in $200 \mu \mathrm{L}$ of distilled water and boiled for 10 min. Tubes were centrifuged again, and the supernatant was used as template DNA. Primer set (Forward 5'- ACG GAG TTA CAA AGG ACG AC-3' and Reverse 5'- AGC TCA GCC TTA ACG AGT AC$3^{\prime}$ ) encoded a $1250 \mathrm{bp}$ product. For PCR amplification, the reaction mixture (30 $\mu \mathrm{L}$ ) contained $1 \mu \mathrm{L}$ of primer $\mathrm{F}$ (10 pmol $/ \mu \mathrm{L}), 1 \mu \mathrm{L}$ of primer $\mathrm{R}(10$ $\mathrm{pmol} / \mu \mathrm{L}), \quad 0.6 \mu \mathrm{L}$ of deoxynucleoside triphosphate (10 mmol/L; Cinna-Gene), $3 \mu \mathrm{L}$ of $10 \times$ PCR buffer (Cinna-Gene), $1.8 \mu \mathrm{L}$ of $\mathrm{MgCl}_{2}(25 \mathrm{mmol} / \mathrm{L}$; CinnaGene), $0.1 \mu \mathrm{L}$ of Taq DNA polymerase (5 U/ $\mu \mathrm{L}$, Cinna-Gene) and $20 \mu \mathrm{L}$ of distilled water. Finally, $2.5 \mu$ l of DNA preparation was added to each $0.2 \mathrm{~mL}$ reaction tube.

Antimicrobial susceptibility test was performed by disk diffusion method on Mueller Hinton agar (CLSI, 2007). The following antibiotics were used: penicillin 
(10 IU), ceftiofur $(30 \mu \mathrm{g})$, ampicillin $(10 \mu \mathrm{g})$, streptomycin $(10 \mu \mathrm{g})$, oxytetracycline $(30 \mu \mathrm{g})$, enrofloxacin $(5 \mu \mathrm{g})$, sulfamethoxazole-trimethoprim (23.75 $\mu \mathrm{g}$ $/ 1.25 \mu \mathrm{g})$, tetracycline $(30 \mu \mathrm{g})$, gentamicin $(10 \mu \mathrm{g})$, lincomycin $(2 \mu \mathrm{g})$, neomycin $(30$ $\mu \mathrm{g})$, tylosin $(30 \mu \mathrm{g})$, florfenicol $(30 \mu \mathrm{g})$. As a quality control a reference strain $(S$. aureus, ATCC 29213) was inoculated in each plate. After $24 \mathrm{~h}$ incubation at $37^{\circ} \mathrm{C}$ plates were examined and the zone of inhibition was measured.

The results indicated that Staphylococcus genus was isolated from 84 among the 420 milk samples collected from suspected quarters. Out of 84 positive samples $50(59.5 \%)$ were reported as coagulase-positive $S$. aureus from which 45 $(90 \%)$ strains were further identified as $S$. aureus by PCR amplification of the specific 23S rDNA gene. The antimicrobial resistance profiles of the $S$. aureus isolates against 13 antimicrobial agents arepresented in Table 1. All S. aureus isolates showed resistance against penicillin and ceftiofur although no resistance has been observed to gentamicin, enrofloxacin and lincomycin. Moreover, resistance to ampicillin, tetracycline, neomycin, tylosin, streptomycin, oxytetracycline, sulfamethoxazole-trimethoprim and florfenicol was reported for $91.1 \%, 84.4 \%, 48.8 \%$, $28.8 \%, 17.7 \%, 11.1 \%, 11.1 \%$ and $2.2 \%$ of isolates respectively. In addition 38 $(84.4 \%)$ of $S$. aureus isolates were resistant to at least 3 antimicrobial agents. (Table 2). Furthermore according to the results $\mathrm{CEF}$, PEN, AMP was the predominant pattern $(22.2 \%)$ among the seven different antimicrobial resistance patterns.

Mastitis is the most common reason for using antimicrobial agents in dairy farms. Antimicrobial resistance is recognised as one of the most significant phe-
Table 1. Antimicrobial resistance of 45 S. aureus bovine subclinical mastitis isolates

\begin{tabular}{lcc}
\hline \multirow{2}{*}{$\begin{array}{l}\text { Antimicrobial } \\
\text { agents }\end{array}$} & \multicolumn{2}{c}{ Resistant isolates } \\
\cline { 2 - 3 } & Number & Percentage \\
\hline Penicillin & 45 & 100.0 \\
Ceftiofur & 45 & 100.0 \\
Ampicillin & 41 & 91.1 \\
Tetracycline & 38 & 84.4 \\
Neomycin & 22 & 48.8 \\
Tylosin & 13 & 28.8 \\
Streptomycin & 8 & 17.7 \\
Oxytetracycline & 5 & 11.1 \\
Sulfamethoxazole- & 5 & 11.1 \\
trimethoprim & & \\
Florfenicol & 1 & 2.2 \\
Gentamicin & 0 & 0 \\
Enrofloxacin & 0 & 0 \\
Lincomycin & 0 & 0 \\
\hline
\end{tabular}

nomena around the world. Increasing antimicrobial resistance of $S$. aureus as the most frequent cause of clinical and subclinical bovine mastitis has been reported in several previous investigations (Daka et al., 2012; Mubarack et al., 2012). In the present study $S$. aureus isolates showed the highest level of resistance to penicillin $(100 \%)$ which was much higher than rates reported in South Africa (20\%), South Ethiopia (67.9\%), Turkey $(63.3 \%)$ and Italy (69.1\%) (Guler et al., 2005'Ateba et al., 2010; Daka et al., 2012). Contrary to our findings, the results of previous studies in Poland and other countries showed lower resistance rates of $S$. aureus to ampicillin ( $7 \%$ to $68.9 \%$ ) (Calvinho et al., 2002; Erskine et al., 2002; Malinowski et al., 2002; Corti et al., 2003; Daka et al., 2012) but a resistance rate higher than ours was reported in Italy (98.5\%) (Moroni et al., 2006). The high resistance rate in Iran can be due to wide usage of $\beta$-lactam antibiotics such as penicillin and ampicillin for the treatment of bovine 
Antimicrobial resistance patterns of Staphylococcus aureus isolated from bovine subclinical mastitis ....

Table 2. Antimicrobial resistance patterns of the $45 \mathrm{~S}$. aureus isolates

\begin{tabular}{lcc}
\hline & \multicolumn{2}{c}{ Multidrug resistance } \\
\cline { 2 - 3 } Antibiotic resistance patterns $^{1}$ & Number & Percentage \\
\hline CEF, PEN, AMP & 10 & 22.2 \\
CEF, PEN, AMP, NEO & 9 & 20.0 \\
CEF, PEN, AMP, NEO, TYL & 6 & 13.3 \\
CEF, PEN, AMP, S & 5 & 11.1 \\
CEF, PEN, AMP, NEO, TYL, FFC, LIN & 3 & 6.6 \\
CEF, PEN, AMP, NEO, TYL, TET, OXT, SXT, S & 3 & 6.6 \\
CEF, AMP, NEO, TYL & 2 & 4.4 \\
\hline Total & 38 & 84.4 \\
\hline
\end{tabular}

${ }^{1}$ PEN: Penicillin; SXT: Sulfamethoxazole-trimethoprim; AMP: Ampicillin; OXT: Oxytetracycline; TE: Tetracycline; S: Streptomycin; GM: Gentamicin; CEF: Ceftiofur; ENR: Enrofloxacin; FFC: Florfenicol; S: Streptomycin; TYL: Tylosin; NEO: Neomycin, LIN: Lincomycin

mastitis although the frequency of $\beta$-lactam antibiotics resistance varies among countries (Guler et al., 2005). The third highest resistance rate occurred against tetracycline $(84.4 \%)$. Lower resistance rate were reported by other researchers (Mubarack et al., 2012; Oliveira et al., 2012). Overuse of antimicrobials for several purposes including treatment and growth promotion in different fields can be the most significant reason for high resistance rates in Iran (Sodagari et al., 2015). Moreover, our data demonstrated that $S$. aureus isolates were more resistant to oxytetracycline, sulfamethoxazole-trimethoprim and less resistant against streptomycin compared to those reported in previous studies (Shitandi \& Sternesjö, 2004; Guler et al., 2005; Mubarack et al., 2012). None of $S$. aureus isolates was resistant against gentamicin, enrofloxacin and lincomycin in the present investigation which is in agreement with results reported in Turkey (Guler et al., 2005), India (Mubarack et al., 2012) and Italy (Moroni et al., 2006) indicating that $S$. aureus isolates are still largely susceptible to these three antimicrobial agents and they can be used effectively in treatment of clinical and subclinical bovine mastitis.

The emergence of multiple drug resistance (MDR) in $S$. aureus strains has become a major challenge in the treatment of bovine mastitis and public health issue (Davies, 1994). Resistance to at least 3 antimicrobial agents was detected in 38 (84.4\%) of $S$. aureus isolates. There are several reports related to MDR in staphylococcal isolates around the world (Gentilini et al., 2002; Guler et al., 2005; Ateba et al., 2010; Daka et al., 2012). In general the high level of MDR in this investigation can be due to overuse and misuse of antimicrobial agents for treatment of mastitis. Poor efficacy of antimicrobial therapy due to poor penetration of scar tissue barriers in animals with chronic $S$. aureus mastitis has been proved (De Oliveira et $a l ., 2000)$. Therefore refusal to insist on treatment of infected cows and culling them from the dairy herds is one of the most reasonable recommendations for decreasing the level of antimicrobial resistance in dairy farms (De Oliveira et al., 2000). Furthermore, carrying out antimicrobial susceptibility test before drug prescription seems necessary. 


\section{REFERENCES}

Ateba C. N., C. C. Bezuidenhout, M. S. Moneoang \& M. Mbewe, 2010. Antibiotic-resistant Staphylococcus aureus isolated from milk in the Mafikeng Area, North West province, South Africa. South African Journal of Science, 106, 1-6.

Balqees, A. A., 2012. Occurrence of sub clinical mastitis in dairy does in Duhok, Iraq. Research Opinions in Animal \& Veterinary Sciences, 2, 69-71.

Barkema, H. W., Y. H. Schukken \& R. N. Zadoks, 2006. Invited review: The role of cow, pathogen, and treatment regimen in the therapeutic success of bovine Staphylococcus aureus mastitis. Journal of Dairy Science, 89, 1877-1895.

Calvinho, L. F., F. G. Toselli, W. R. Weimann, V. R. Canavesio, V. E. Neder \& I. A. Iguzquiza, 2002. Antimicrobial sensitivity of coagulase-positive staphylococcal strains isolated from bovine mastitis in the central dairy catchment area of Argentina. Revista Argentina de Microbiología, 34,171-175.

CLSI, 2007. Performance Standards for Antimicrobial Susceptibility Testing. CLSI Approved Standards M100-S15. 2007. Clinical and Laboratory Standards Institute, Wayne, PA. CDC. USA

Corti, S., D. Sicher, W. Regli \& R. Stephan, 2003. Current data on antibiotic resistance of the most important bovine mastitis pathogens in Switzerland. Schweizer Archiv für Tierheilkunde, 145, 571-575.

Daka, D., S. G. Silassie \& D. Yihdego, 2012. Antibiotic-resistance Staphylococcus aureus isolated from cow's milk in the Hawassa area, South Ethiopia. Annals of Clinical Microbiology and Antimicrobials, 11, 26.

Davies, J., 1994. Inactivation of antibiotics and the dissemination of resistance genes. Science, 264, 375-382.

De Oliveira, A. P., J. L. Watts, S. A. Salmon \& F. M. Aarestrup, 2000. Antimicrobial susceptibility of Staphylococcus aureus isolated from bovine mastitis in Europe and the United States. Journal of Dairy Science, 83, 855-862.

Donovan, D. M., D. E. Kerr \& R. J. Wall, 2005. Engineering disease resistant cattle. Transgenic Research, 14, 563-567.

Erskine, R. J., R. D. Walker, C. A. Bolin, P.C Bartlett \& D. G. White, 2002. Trends in antibacterial susceptibility of mastitis pathogens during a seven-year period. Journal of Dairy Science, 85, 1111-1118.

Gao, J., M. Ferreri, F. Yu, X. Liu, L. Chen, J. Su \& B. Han, 2012. Molecular types and antibiotic resistance of Staphylococcus aureus from bovine mastitis in a single herd in China. The Veterinary Journal, 192, 550-552.

Gentilini, E., G. Denamiel, P. Liorente, S. Godaly, M. Rebuelto \& O. De Gregorio, 2000. Antimicrobial susceptibility of Staphylococcus aureus isolated from bovine mastitis in Argentina. Journal of Dairy Science, 83, 1224-1227.

Gentilini, E., G. Denamiel \& A. Betancor, 2002. Antimicrobial susceptibility of coagulase-negative staphylococci isolated from bovine mastitis in Argentina. Journal of Dairy Science, 85, 1913-1917.

Guler, L., U. Ok, K. Gunduz, Y. Gulcu \& H. H. Hadimli, 2005. Antimicrobial susceptibility and coagulase gene typing of Staphylococcus aureus isolated from bovine clinical mastitis cases in Turkey. Journal of Dairy Science, 88, 3149-3154.

Hosseinzadeh, S. \& H. Dastmalchi Saei, 2014. Staphylococcal species associated with bovine mastitis in the North West of Iran: Emerging of coagulase-negative staphylococci. International Journal of Veterinary Science and Medicine, 2, 27-34.

Huijps, K., T. J. Lam \& H. Hogeveen, 2008. Costs of mastitis: Facts and perception. Journal of Dairy Research, 75,113-120.

Jorgensen, H., T. Mork, H. Hogasen \& L. Rorvik, 2005. Enterotoxigenic Staphylococcus aureus in bulk milk in Norway. Journal of Applied Microbiology, 99, 158-166.

Leitner, G., N. Silanikove, S. Jacobi, L. Weisblit, S. Bernstein \& U. Merin, 2008. 
Antimicrobial resistance patterns of Staphylococcus aureus isolated from bovine subclinical mastitis ....

The influence of storage on the farm and in dairy silos on milk quality for cheese production. International Dairy Journal, 18, 109-113.

Lowy, F. D., 2003. Antimicrobial resistance: The example of Staphylococcus aureus. Journal of Clinical Investigation, 111, 1265-1273.

Malinowski, E., A. Klossowska, M. Kaaczmarowski, H. Lassa \& K. Kuzma, 2002. Antimicrobial susceptibility of staphylococcus isolated from affected with mastitis cows. Bulletin of the Veterinary Institute in Pulawy, 46, 289-294.

Moroni, P., G. Pisoni, M. Antonini, R. Villa, P. Boettcher \& S. Carli, 2006. Antimicrobial drug susceptibility of Staphylococcus aureus from subclinical bovine mastitis in Italy. Journal of Dairy Science, 89, 2973-2976.

Mubarack, H. M., A. Doss, M. Vijayasanthi \& R. Venkataswamy, 2012. Antimicrobial drug susceptibility of Staphylococcus aureus from subclinical bovine mastitis in Coimbatore, Tamilnadu, South India. Veterinary World, 5, 352-355.

Oliveira, L., H. Langoni, C. Hulland \& P. L. Ruegg, 2012. Minimum inhibitory concentrations of Staphylococcus aureus recovered from clinical and subclinical cases of bovine mastitis. Journal of Dairy Science, 95, 1913-1920.

Pitkala, A., M. Haveri, S. Pyorala, V. Myllys \& T. Honkanen-Buzalski, 2004. Bovine mastitis in Finland 2001 - prevalence, distribution of bacteria, and antimicrobial resistance. Journal of Dairy Science, 87, 2433-2441.

Rahim, B., S. Jala, E. Behrad, G. Jamshid \& M. Naser, 2010. Prevalence and etiology of sub clinical mastitis in Ewes of the Tabriz Region, Iran. Global Veterinaria, 4 , 299-302.

Sahebekhtiari, N, Z. Nochi, M. A. Eslampour, H. Dabiri, M. Bolfion, M. Taherikalani, B. Khoramian, M. R. Zali \& M. Emaneini, 2011. Characterization of Staphylococcus aureus strains isolated from raw milk of bovine subclinical mastitis in Tehran and Mashhad. Acta Microbiologica et Immunologica Hungarica, 58, 113-121.

Seleim, R. S., Y. M. Rashed \& B. G. A. Fahmy, 2002. Mastitis pathogens attachment-related virulence features, whey protein markers and antibiotic efficacy in cows. Veterinary Medical Journal (Giza), 50, 405-409.

Sharma, N., 2007. Alternative approach to control intramammary infection in dairy cows - a review. Asian Journal of Animal and Veterinary Advances, 2, 50-62.

Shitandi, A. \& A. Sternesjö, 2004. Prevalence of multidrug resistant Staphylococcus aureus in milk from large- and small-scale producers in Kenya. Journal of Dairy Science, 87, 4145-4149.

Sodagari, H. R., Z. Mashak \& A. Ghadimianazar, 2015. Prevalence and antimicrobial resistance of Salmonella serotypes isolated from retail chicken meat and giblets in Iran. The Journal of Infection in Developing Countries, 9, 463-469.

Straub, J. A., C. Hertel \& W. P. Hammes, 1999. A $23 \mathrm{~S}$ rDNA-targeted polymerase chain reaction-based system for detection of Staphylococcus aureus in meat starter cultures and dairy products. Journal of Food Protection, 62, 1150-1156.

Taponen, S., H. Simojoki, M. Haveri, H. D. Larsen \& S. Pyorala, 2006. Clinical characteristics and persistence of bovine mastitis caused by different species of coagulase-negative staphylococci identified with API or AFLP. Veterinary Microbiology, 115, 199-207.

Paper received 09.02.2015; accepted for publication 08.05.2015

\section{Correspondence:}

Hadi Pourtaghi

Department of Microbiology, Karaj Branch, Islamic Azad University, Karaj, Iran, e-mail: hadi.pourtaghi1@gmail.com 